\title{
Produção textual em RP a partir da perspectiva de gêneros do discurso: um estudo inicial
}

\author{
PR text production from discourse genres perspective: an initial study
}

\begin{abstract}
Aline Ferreira Lira
Mestre em Ciências Ambientais, professora assistente do curso de Relações Públicas da Universidade Federal do Amazonas (UFAM), Doutoranda em Linguística pela Universidade Federal de Santa Catarina (UFSC), Manaus, AM - Brasil, e-mail: aline@ufam.edu.br; aline_lira@yahoo.com
\end{abstract}

\section{Resumo}

Este artigo pretende discutir a utilização da concepção de gêneros do discurso para o ensino de produção textual em Relações Públicas, a partir de uma pesquisa bibliográfica. Como a maioria dos cursos oferecidos pelas instituições de nível superior nesta área utiliza ainda o ensino de redação, inicialmente discutem-se as implicações dessa troca de termos e de conceitos para então apresentar-se uma proposta de processo de elaboração didática para o ensino de produção textual em Relações Públicas. Este estudo é feito baseado em autores como Bakhtin, Rodrigues, Geraldi e Kunsch e aponta para a necessidade de pesquisas na área, já que a opção por produção textual implicaria uma série de mudanças no curso, inclusive paradigmáticas.

Palavras-chave: Gênero do discurso. Produção textual. Ensino. Relações Públicas.

\section{Abstract}

The proposal of this article is to discuss how discourse genre conception could be used for PR textproduction teaching, using for this a bibliographic research. As the most of the PR courses in this area still teach writing instead of text production, firstly it's discussed this change of terms and concepts; then, a proposal of didactic elaboration for text production teaching in PR is presented. This study is based on authors such as Bakbtin, Rodrigues, Geraldi and Kunsch and indicates the necessity on research in this area, since the option for text production would implicate in a series of changes in PR course, including paradigmatic ones.

Keywords: Discourse genres. Text production. Teaching. Public Relations. 


\section{Introdução}

As Relações Públicas são uma atividade do campo da Comunicação Social que visam, principalmente, à gestão do relacionamento de uma organização, seja ela pública ou privada, com os seus diversos públicos. Para isso, segundo o Conselho Federal dos Profissionais de Relações Públicas (BRASIL, 2002), são utilizadas a comunicação estratégica, a comunicação integrada e a comunicação dirigida. A primeira direciona esforços para que os objetivos globais da organização sejam cumpridos, principalmente em relação à sua imagem. Já a comunicação integrada ${ }^{1}$ garante que todas as áreas da comunicação organizacional (comunicação interna, administrativa, institucional e mercadológica) tenham, apesar de suas particularidades, uma mensagem única, para que a imagem organizacional seja percebida como uma só pelos seus públicos.

Já com a comunicação dirigida, ao contrário da comunicação de massa, pretendem-se criar instrumentos de comunicação ${ }^{2}$ destinados a cada um dos públicos com os quais a organização mantém ou pretende manter relacionamento, a partir das opiniões e atitudes destes: empregados, fornecedores, imprensa, governo, sociedade, comunidade, etc. Isso, na Universidade Federal do Amazonas (UFAM), é ensinado aos alunos por meio de duas disciplinas diferentes: Técnicas de Redação Aplicada às Relações Públicas, ministradas durante quatro períodos, em que os alunos deveriam aprender os aspectos formais de escrita dos instrumentos; e Técnicas de Comunicação Dirigida, ministradas durante dois períodos, em que os alunos deveriam, após aprender o aspecto formal dos instrumentos, aplicá-los no processo de relacionamento com os diversos públicos, conforme mencionado anteriormente.

Fiorin (2006) esclarece que Bakhtin nãoleva em conta o produto, mas o processo de sua produção e a maneira como ele se constitui. No ensino de redação em Relações Públicas, ao contrário, as propriedades formais e os aspectos normativos são mais importantes que a construção do enunciado em si. O objetivo deste artigo, portanto, é discutir o ensino de Relações Públicas, mais especificamente a produção textual a partir da concepção de gêneros na perspectiva dialógica da linguagem.

\section{Da redação à produção textual nas prátícas pedagógicas de relações públicas}

Rodrigues (2005) destaca que, embora o foco central do Círculo de Bakhtin não tenha sido o ensino/aprendizado de línguas, as concepções teóricas desse grupo estão de acordo com as discussões estabelecidas na área, desde meados da década de 1980. Dessa forma, pode-se concluir que o ensino de produção textual em Relações Públicas também poderia apropriar-se da concepção de gênero e da perspectiva dialógica da linguagem com vistas ao melhor domínio dessa atividade por parte dos alunos do curso.

Para que isso aconteça, uma das primeiras ações seria a migração do termo redação em Relações Públicas para produção textual em Relações Públicas. Essa substituição de termos ocorreu, no ensino de Língua Portuguesa, já na década de 1980 (GERALDI, 2004) e, apesar das expressões serem aparentemente sinônimas e designarem o fenômeno de redigir textos (GUEDES, 2009), cada uma delas possui uma conotação diferente que precisa ser considerada por professores da área:

Distinguem-se [...] por se vincularem a teorias que expressam diferentes formas de considerar não só a ação de escrever textos, a ação de ensinar a escrever textos e a ação de exercitar a linguagem, mas também a própria organização social (GUEDES, 2009, p. 88).

O autor esclarece que a expressão redação está relacionada à eficiência de profissões tecnocráticas que atuam nas organizações (engenharias, economia, administração, etc.) e que, no período dos anos 1950, representavam o emblema da sociedade brasileira. Por serem uma atividade administrativa, que desenvolve ações com vistas ao melhor desempenho

\footnotetext{
1 Sobre comunicação integrada, ver Kunsch (2003).

2 Na área de Relações Públicas, quando se trabalha com instrumentos de comunicação, não se diferencia gênero do discurso de suporte.
} 
organizacional, a partir da aceitação e do consentimento dos públicos e do constante reforço da imagem institucional, pode-se inferir que as Relações Públicas absorveram essa cultura de eficiência citada por Guedes (2009).

Daí advém, também, segundo o autor, a influência da ideia de que linguagem é apenas um meio de comunicação,

um código pelo qual o emissor cifra a sua mensagem, que será decifrada pelo receptor, caso não haja ruídos no canal de comunicação por meio da qual é transmitida. Tudo muito limpo, muito organizado, bastando um bom trabalho de manutenção (GUEDES, 2009, p. 89).

A redação, portanto, está intimamente relacionada com a perspectiva de organizar o pensamento, de fazer-se claro, conciso e direto para que o receptor consiga acessar a mensagem com o mínimo de ruídos possível. E essa é uma constante não só no ensino de Relações Públicas, mas também em sua prática profissional.

Moura (2001), por exemplo, realizou uma pesquisa com docentes das várias habilitações de Comunicação, incluindo Relações Públicas, e 80\% dos entrevistados indicaram que Redação e Expressão Oral seria uma disciplina importante para os alunos do curso. Além disso, nas diretrizes curriculares propostas pela autora, há a indicação de Redação e Expressão em Relações Públicas como disciplina específica para o curso. Ferreira (2008) indica que em Santa Catarina 66,66\% dos cursos de Relações Públicas oferecem a disciplina Redação em Relações Públicas. Essa é a realidade de cursos de Relações Públicas de diversas instituições de nível superior, inclusive a Universidade Federal do Amazonas. E tal realidade pode ser mudada para que os alunos do curso tenham maior domínio sobre o que escrevem e compreendam as implicações dialógicas decorrentes disso.

Nesse caso, a produção de textos, como um processo de transformação provocado pela ação humana, seria a proposta de ensino mais indicada para as Relações Públicas.

Ao se propor a produção de textos como a devolução da palavra ao sujeito, aposta-se no diálogo (que não exclui a polêmica e a luta pelos sentidos), e na possibilidade de recuperar na "história contida e não contada" elementos indicativos do novo que se imiscui nas diferentes formas de retomar o vivido, de inventar o cotidiano (GERALDI, 2004, p. 20).

Com essa possibilidade de devolução da palavra ao sujeito, que é visto como alguém que é "produto da ação cultural, mas também de suas ações sobre ela" (GERALDI, 2004, p. 20), a perspectiva do público, que, como receptor, recebe e aceita mensagens da organização (emissor), deixa de existir. A partir disso, passam a existir interlocutores. "Produção de texto pressupõe leitores que vão dialogar com o texto produzido: concordar e aprofundar ou discordar e argumentar, tomando o texto como matéria-prima para o seu trabalho" (GUEDES, 2009, p. 90).

Para Bakhtin (2003), tratar a comunicação discursiva como um processo em que há um "falante" ativo e um "ouvinte" passivo é mera ficção, um momento abstrato da compreensão.

Neste caso, o ouvinte, ao perceber e compreender o significado (lingüístico) do discurso, ocupa simultaneamente em relação a ele uma ativa posição responsiva: concorda ou discorda (total ou parcialmente), completa-o, aplica-o, prepara-se para usá-lo etc; essa posição responsiva do ouvinte se forma ao longo de todo o processo de audição e compreensão desde o seu início, às vezes literalmente a partir da primeira palavra do falante (BAKHTIN, 2003, p. 271).

E é justamente aí que reside um problema para a área das Relações Públicas: como, em todas as áreas de estudos relacionadas à Comunicação Social, o paradigma de processo de comunicação ainda é presente, e prejudica a aplicação do conceito de dialogismo proposto por Bakhtin? A princípio, isso parece ser um paradoxo para a área, já que o diálogo é a base do estabelecimento e manutenção de relacionamento entre a organização e seus diversos públicos.

Entretanto, para as Relações Públicas, o diálogo não existe nos textos em que se escreve, e sim nos momentos que antecedem ou que vêm depois do contato com estes. O diálogo, aliás, para as Relações Públicas, tem o objetivo primeiro de estabelecer a compreensão, a aceitação e o consenso, excluindo totalmente a polêmica e a luta pelos sentidos preconizadas por Geraldi (2004). Corroborando 
com essa perspectiva, Faraco (2009) destaca que os integrantes do Círculo de Bakhtin não são teóricos do consenso. Das relações dialógicas "pode resultar tanto a convergência, o acordo, a adesão, o mútuo complemento, a fusão, quanto a divergência, o desacordo, o embate, o questionamento, a recusa" (FARACO, 2009, p. 68).

Portanto, assumir a produção textual para as Relações Públicas implica não somente adotar uma "nova" abordagem pedagógica, mas, principalmente, uma mudança de paradigmas que poderá transformar a práxis da área. Kunsch (2009) indica que, entre os paradigmas vigentes para as Relações Públicas e a comunicação organizacional, o modelo mecanicista, que trabalha a comunicação organizacional sob a perspectiva funcionalista e da eficácia organizacional, é o que predomina.

Cremos que, mesmo em pleno terceiro milênio, as organizações não mudaram muito seu comportamento. Muitas vezes, elas têm uma retórica moderna, mas suas atitudes e ações comunicativas são ainda impregnadas por uma cultura tradicional e autoritária do século XIX (KUNSCH, 2009, p. 72).

De acordo com a autora, a adoção da perspectiva crítica, que trabalha as relações de poder e que depende de uma visão dialética, é mais complexa e exige das organizações outra maneira de relacionarse com os públicos. A opção por adotar-se o que Bakhtin (2003) chamou de abstração científica, na verdade, reflete a necessidade de as organizações, por meio das atividades e técnicas de Relações Públicas, estabelecerem um diálogo também fictício, porque na verdade não abre espaço para o dissenso. Ao optar-se por emissores e receptores nos seus processos de comunicação, as organizações tentam justamente suprir dos públicos o direito de discordar do que está sendo posto como "oferta" no processo de relacionamento com a organização. "O esquema deforma o quadro real da comunicação discursiva, suprimindo dela precisamente os momentos mais substanciais. Desse modo, o papel ativo do outro no processo de comunicação discursiva fica enfraquecido" (BAKHTIN, 2003, p. 273).

Entretanto, Peruzzo (1986) iniciou outra perspectiva de estudos para a área de Relações Públicas no Brasil, que prevê a utilização de instrumentos e técnicas da área para a promoção da emancipação social das minorias. A partir de então, são vários os estudiosos que se dedicam a essa perspectiva da área; contudo, as organizações, principalmente as privadas, ainda trabalham com a perspectiva mecanicista, $\mathrm{o}$ que afeta diretamente a práxis da área e o seu ensino, inclusive de produção textual.

Propor, portanto, que os cursos de Relações Públicas adotem a produção textual, ao invés da redação, implica repensar que tipo de aluno se está formando: se um mero repetidor das técnicas que comprovadamente não possibilitam um domínio completo dos instrumentos de comunicação dirigida ou um profissional com uma visão crítica e transformadora da realidade e com maior domínio, inclusive, dos processos de relacionamento com cada um dos públicos.

\section{O ensino da produção textual de Relações Públicas: o papel dos gêneros do discurso}

A noçãodegêneros dodiscurso como objeto de ensino surgiu na década de 1990 (RODRIGUES, 2005, p. 171), a partir do entendimento de que o texto "é construído segundo certas condições sociais, certos modos sociais de dizer e agir".

Trabalhar com a noção de gêneros do discurso, no quadro teórico do Círculo, é não desvincular essa noção do escopo mais amplo da teoria, que é pensar a linguagem no campo das relações sociais, portanto, marcada ideologicamente, concebida como interação e sempre perpassada pelas relações dialógicas (RODRIGUES, 2008, p. 171).

Embora o gênero seja utilizado como mediador de ensino/aprendizado de línguas, em Relações Públicas esse papel vai mais além. A produção textual a partir do conceito de gêneros do discurso deve ser apreendida para que se transforme em prática profissional futura. Portanto, a compreensão de suas características e das possibilidades de dialogismo deve ser mais ampla. Ou seja, o aluno de Relações Públicas precisa ter conhecimento das possibilidades de efeito de sentido que os textos por ele produzidos podem gerar.

Para isso, é importante, para o ensino de produção textualde Relações Públicas, o levantamento 
de quais gêneros são utilizados nas organizações para que os estudantes do curso possam ter um convívio com as possibilidades que irão entrar em contato no mercado de trabalho. É importante destacar, no entanto, que não seria indicado fazer uma classificação de gêneros, e sim apenas um levantamento, pois mais interessante é a compreensão destes e as influências que eles podem exercer a partirdo processo responsivo que geram. Bakhtin (2003, p. 283) esclarece que há uma ausência de classificação bem pensada de gêneros por campo de atividade e, considerando que as formas do gênero "são bem mais flexíveis, plásticas e livres que as formas da linguagem, classificá-los poderia ser um trabalho inócuo, já que os gêneros do discurso estão em constante transformação e vão se diferenciando à medida que as esferas vão ficando mais complexas (FARACO, 2009).

De acordo com Fiorin (2006), é um equívoco pensar os gêneros como um conjunto de propriedades formais que se deve obedecer no texto. Isso já acontece, por exemplo, nas aulas de redação em Relações Públicas, em que as propriedades formais e os aspectos normativos são mais importantes que a construção do enunciado em si. Ensinar a produção textual a partir da elaboração de um produto pronto, acabado, não dá conta do natural processo de mudança histórica que envolve os gêneros do discurso.

Outro aspecto que se deve considerar ao adotar-se a produção textual no ensino de Relações Públicas é o papel do professor e do aluno nesse processo. Geraldi (1997, p. 221-222) afirma que o professor deve abandonar "a posição de guardar para si o território de detentor/transmissor de um saber para se colocar, com os alunos em outro território: o da construção de reflexões".

Portanto, deve-se levar em conta o conhecimento que o aluno de Relações Públicas já possui para "construir um sentido rearticulando seus saberes deslocados em função dos novos conteúdos aprendidos" (GERALDI, 2004, p. 20). Ora, não faz o aluno de Relações Públicas parte de uma comunidade, não é ele um cliente, não é ele muitas vezes funcionário de uma organização? O contato que ele tem com gêneros, nesses momentos, deveria ser levado em conta ao ensinar-se a produzir textos na área.
Professores e alunos são portadores de diferentes saberes e estes precisam ser compartilhados. "Somente uma crença ideológica de que esses conhecimentos imutáveis (por que científicos?) torna-nos surdos aos saberes 'mudos' que estão presentes na vida dos alunos" (GERALDI, 2004, p. 21). Adotar essa postura seria assumir que os gêneros não são plásticos e que não estão em constante transformação.

Considerando os aspectos acima relacionados e com base em Rodrigues (2005), ${ }^{3}$ é apresentada, aqui, uma proposta de processo de elaboração didática para o ensino de produção textual em Relações Públicas. Importa dizer que essa elaboração didática dever ser feita de forma interdisciplinar, principalmente com Técnica de Relações Públicas, Técnica de Comunicação Dirigida e Planejamento em Relações Públicas, para que o aluno tenha um melhor domínio da esfera sociodiscursiva da área.

1) Busca de conbecimento de referência sobre o gênero do discurso - o professor deve fazer uma análise comparativa entre os principais autores de Relações Públicas e comunicação organizacional, para verificar como esses gêneros são apresentados e classificados de acordo com a perspectiva de comunicação dirigida ou de massa. Em seguida, é necessário fazer uma análise para verificar se os instrumentos selecionados são, de fato, gêneros ou se são apenas suporte. Outra informação que se deve buscar, nesse momento, é a identificação do paradigma teórico dos autores consultados; é interessante trabalhar não só com autores funcionalistas, mas também com autores das perspectivas crítica e interpretativa, conforme apontado por Kunsch (2009).

2) Seleção de textos - nesta fase, é importante que o banco de dados seja formado com os mais variados instrumentos de comunicação dirigida de organizações do primeiro, segundo e terceiro setores, para que se possa, ao trabalhar na perspectiva dos gêneros, ter contato com as diversas formações discursivas a que esses gêneros pertencem. "A seleção objetiva trabalhar com textos diversos, que consigam dar conta da relativa estabilidade e heterogeneidade

3 Ética, moral da história narrada, segundo Comparato (2007). 
do gênero" (RODRIGUES, 2008, p. 173). Neste momento, também é importante considerar não só os gêneros impressos tradicionais, mas também as mídias sociais, particularmente os blogs, os sites corporativos, o Twitter $^{4}$ e, se possível, o Yammer. ${ }^{5}$

3) Prática de leitura do texto como enunciado - é neste momento, segundo Rodrigues (2008), que o aluno é colocado no papel de interlocutor do gênero. Portanto, seria interessante que entrasse em contato com a perspectiva dialógica da linguagem, para que tenha uma melhor compreensão das interações possíveis decorrentes de um texto.

4) Prática de leitura-estudo do texto e do gênero aqui, será feita uma investigação a respeito da instituição que produziu o gênero (de qual setor, de que nacionalidade, para que público se destinou o gênero e, se possível, quais as características desse público), para que se compreenda a esfera de produção do gênero e como se deu a interlocução a partir dele.

5) Prática de produção textual - nesta etapa, deveria ser selecionada uma instituição para que se produza o gênero em questão a partir de uma situação real. Entretanto, como para as Relações Públicas a produção de instrumentos de comunicação não pode ser isolada de um processo de planejamento, é indicado que esse trabalho seja realizado em conjunto com as disciplinas que trabalham com esse tema.

6) Prática de revisão e reescrita de textos - essa atividade poderia ser realizada em grupo, com o acompanhamento do professor. Dessa forma, os alunos teriam contato com os textos de seus pares, o que poderia dar a eles outras perspectivas de produção textual do mesmo gênero.

\section{Conclusão}

A Associação Brasileira de Relações Públicas (ABRP) define Relações Públicas como "a atividade e o esforço deliberado, planejado e contínuo para estabelecer e manter a compreensão mútua entre uma instituição pública ou privada e o grupo de pessoas a que esteja direta ou indiretamente ligada" (PERUZZO, 1986, p. 33). Pode-se concluir que as Relações Públicas implicam uma atividade planejada, que visa a obter a aceitação social mútua entre a empresa e seus públicos, para que sejam asseguradas relações confiáveis e duradouras. E, por isso, visa à institucionalização da empresa.

Para o estabelecimento dessa relação com os diversos públicos da organização, as Relações Públicas utilizam-se da comunicação de mão dupla, baseada em pesquisas e alinhada com os objetivos, as estratégias, a missão e os valores da empresa. Ao mesmo tempo em que é necessário garantir que as mensagens estejam de acordo com as expectativas de cada um dos públicos, há necessidade de integrar-se as mensagens para que não haja conflito entre elas.

Para desenvolver essas atividades, como já foi dito, é necessário estabelecer um processo de planejamento, que deve estar baseado em pesquisa. Esta é que define quais são as expectativas e opiniões dos públicos com relação à organização. Mesmo assim, os públicos não são vistos como interlocutores dos enunciados que as organizações produzem por meio dos seus vários gêneros.

Bakhtin (2003, p. 301) afirma que o papel dos outros, a quem se destina o enunciado (aí poderíamos, em Relações Públicas, dizer públicos), é ativo. "Não são ouvintes passivos mas participantes ativos da comunicação discursiva. Desde o início o falante aguarda a resposta deles, espera uma ativa compreensão responsiva".

Assumir o ensino de produção textual em Relações Públicas a partir da concepção dialógica dos gêneros, portanto, implica considerar outros aspectos teóricos e metodológicos que precisam ainda ser estudados e discutidos entre os professores da área para a sua efetiva implementação. Não se pretende com este estudo, portanto, trazer as respostas necessárias para que isso seja efetivado. $\mathrm{Na}$ verdade, este estudo inicial acaba por apontar a necessidade de pesquisa nessa área.

\footnotetext{
4 Microblog em que se postam mensagens de até 140 caracteres e o autor tem, em sua página, a possibilidade de ler não apenas o que ele escreve, mas também o que é produzido por seus seguidores.

5 O Yammer é um microblog com as mesmas características do Twitter. Entretanto, ele é fechado para uma organização apenas, com acesso exclusivo dos integrantes dessa instituição.
} 
Primeiramente, deveriam serinvestigadas as práticas de ensino de redação em Relações Públicas nas salas de aula para se verificar se, apesar do nome, não poderiam haver ações mais relacionadas à produção textual, o que poderia facilitar a implementação da concepção dialógica dos gêneros do discurso como objeto de ensino. Seria importante, também, neste estudo, verificar como se dá o aprendizado dos alunos nesse processo.

As implicações teóricas, metodológicas e epistemológicas da adoção, por parte dos cursos de Relações Públicas, dessa perspectiva de ensino também mereceriam ser objeto de investigação.

Por fim, este é um momento propício para se analisar as implicações do ensino de produção textual a partir da concepção de gêneros do discurso, já que o Ministério da Educação está estabelecendo os novos parâmetros curriculares para os cursos de Comunicação Social, inclusive de Relações Públicas. Dessa forma, seria possível verificar a possibilidade de adotar-se uma prática pedagógica que representaria um avanço não só na academia, mas que também teria um reflexo importante na atuação de futuros profissionais da área.

\section{Referências}

BAKHTIN, M. Estética da criação verbal. 4. ed. São Paulo: Martins Fontes, 2003.

BRASIL. Conselho Federal de Profissionais de Relações Públicas. Resolução Normativa n. 43, de 24 de agosto de 2002. Define as funções e atividades privativas de Relações Públicas. Diário Oficial [da] República Federativa do Brasil, Brasília, DF, Seção I, p. 190, 28 out. 2002. Disponível em: $<$ http: / www.conferp.org.br/?p=407>. Acesso em: 21 jan. 2010.

FARACO, C. A. Linguagem \& diálogo: as ideias linguísticas do Círculo de Bakhtin. São Paulo: Parábola, 2009.

FERREIRA, E. do A. O ensino das relações públicas em Santa Catarina. In: MOURA, C. P. de (Org.). História das Relações Públicas: fragmentos da memória de uma área. Porto Alegre: EDIPUCRS, 2008. p. 52-72.

FIORIN, J.L. Introdução ao pensamento de Bakhtin. São Paulo: Ática, 2006.

GERALDI, J. W. Portos de passagem. 4. ed. São Paulo: Martins Fontes, 1997.
GERALDI, J. W. Da redação à produção de textos. In: GERALDI, J. W.; CITELLI, B. (Coord.). Aprender e ensinar com textos de alunos. 6. ed. São Paulo: Cortez, 2004. v. 1, p. 121-143.

GUEDES, P. C. Da redação à produção textual: o ensino da escrita. São Paulo: Parábola, 2009.

KUNSCH, M. M. K. Planejamento de relações públicas na comunicação integrada. São Paulo: Summus, 2003.

KUNSCH, M. M. K. Percursos paradigmáticos e avanços epistemológicos nos estudos de comunicação organizacional. In: KUNSCH, M. M. K. Comunicação organizacional: histórico, fundamentos e processos. São Paulo: Saraiva, 2009. v. 1, p. 63-89.

MOURA, C. P. de. Ensino de relações públicas: uma proposta de estrutura curricular. In: CONGRESSO BRASILEIRO DA COMUNICAÇÃO-SOCIEDADE BRASILEIRADEESTUDOSINTERDISCIPLINARES DA COMUNICAÇÃO, 24., 2001, Campo Grande, MS. Anais... Campo Grande, MS: INTERCOM, 2001. Disponível em: <www.intercom.org.br>. Acesso em: 21 jan. 2010.

PERUZZO, C. K. Relações públicas no modo de produção capitalista. São Paulo: Summus, 1986.

RODRIGUES, R. H. Os gêneros do discurso na perspectiva dialógica da linguagem: a abordagem de Bakhtin. In: MEURER, J. L.; BONINI, A.; MOTTA-ROTH, D. (Org.). Gêneros: teorias, métodos, debates. São Paulo: Parábola, 2005. p. 152-183.

RODRIGUES, R. H. Pesquisa com os gêneros do discurso na sala de aula: resultados iniciais. Acta Scientiarum: Language and Culture, v. 30, n. 2, 2008. Disponível em: <http://www.periodicos.uem.br/ojs/index.php/ ActaSciLangCult/index>. Acesso em: 20 jan. 2010.

Recebido: 26/03/2010 Received: 03/26/2010

Aprovado: $12 / 04 / 2010$ Approved: 04/12/2010 